\title{
BMJ Open Years of life lost due to diseases of the digestive system in Poland according to socioeconomic factors: a cross- sectional study
}

\author{
Paulina Paciej-Gołębiowska, ${ }^{\oplus}$ Małgorzata Pikala, Irena Maniecka-Bryła
}

To cite: Paciej-Gołębiowska P, Pikala M, Maniecka-Bryła I. Years of life lost due to diseases of the digestive system in Poland according to socioeconomic factors: a crosssectional study. BMJ Open 2019;9:e030304. doi:10.1136/ bmjopen-2019-030304

- Prepublication history and additional material for this paper are available online. To view these files, please visit the journal online (http://dx.doi org/10.1136/bmjopen-2019030304).

Received 08 March 2019 Revised 01 August 2019 Accepted 02 August 2019
Check for updates

(C) Author(s) (or their employer(s)) 2019. Re-use permitted under CC BY-NC. No commercial re-use. See rights and permissions. Published by BMJ.

Department of Epidemiology and Biostatistics, Medical University of Lodz, Łódź, Poland

\section{Correspondence to} Dr Paulina Paciej-Gołębiowska; paulina.paciej@stud.umed. lodz.pl

\section{ABSTRACT}

Objectives To analyse years of life lost (YLLs) due to digestive diseases in Poland according to: marital status, education, working status and place of residence.

Design A cross-sectional study.

Setting The study was based on a dataset containing information from death certificates of Poles who died in 2002 and in 2011.

Participants The analysis covered records with codes K00-K93 according to the International Classification of Diseases and Related Health Problems, 10th Revision. Outcome measures YLL values were calculated using the Standard Expected Years of Life Lost measure. For each socioeconomic variable, the rate ratio (RR) was calculated as the quotient of YLLs in the less privileged group to the more privileged group.

Results Among the categories of marital status, the smallest YLL values (per 10000 ) were recorded among singles (men: 100.63 years in 2002, 121.10 years in 2011 women: $26.99,33.33$, respectively), and the most among divorced men $(657.87,689.32)$ and widowed women (173.97, 169.46). YLL analysis according to education level revealed the lowest values in people with higher education (men: 54.20, 57.66; women: 17.31, 18.31) and the highest in people with lower than secondary education (men: 178.85, 198.32; women: 104.95, 125.76). Being economically active was associated with a smaller YLL score (men: 39.93, 59.51; women: $10.31,14.96)$ than being inactive (men: 340.54, 219.93; women: 126.86, 96.80). Urban residents had higher YLL score (men: $159.46,174.18$, women: $73.03,78.12$ ) than rural ones (men: 126.83, 137.11, women: 57.32, 57.56).

In both sexes, RR according to education level and place of residence increased, and those according to marital status and working status decreased with time.

Conclusions Activities aimed at reducing health inequalities in terms of YLL due to digestive diseases should be primarily addressed to inhabitants with lower than secondary education, divorced and widowed people, urban residents and those who are economically inactive.

\section{INTRODUCTION}

Globally, life expectancy is increasing, reflecting the improvement in the health of the population. According to the Global Burden of Disease (GBD) study, between
Strengths and limitations of this study

- The research material was a complete database containing information from all death certificates of Polish citizens from 2002 ( $n=359486$ ) and 2011 $(n=375501)$, from which records encoded as K00K93 were used for further analysis (17 772 and 16434 deaths, respectively).

- The methodology used in this study allows the resulting year of life lost (YLL) score to be compared with those found for other populations.

- The study included the years 2002 and 2011, that is, the years in which the last two national censuses took place, these being the data sources.

- YLLs according to socioeconomic variables were calculated for people aged 15 and above, because data from censuses on marital status, level of education and working status were limited to this age group.

- The data on the level of education were absent from $0.47 \%$ of deaths certificates in 2002 and $1.50 \%$ in 2011; data on marital status were absent in $0.24 \%$ of cases in 2011 but were complete in 2002; working status was absent from $0.37 \%$ of certificates from 2002 and $1.41 \%$ of certificates in 2011 ; data on the place of residence were complete in both studied years.

1980 and 2015, global life expectancy increased from 59.6 to 69.0 years among men and from 63.7 to 74.8 years among women. ${ }^{1}$ In view of these positive trends, the existence of differences in health between individual countries and specific socioeconomic groups is of concern. In 2005, WHO appointed the Commission for Social Determinants of Health, which confirmed the significance of this problem. ${ }^{2}$

In Poland, a country with a life expectancy shorter than the European Union (EU) average, that is, 73.5 years in men and 81.6 years in women, compared with 77.9 and 83.3 years for the EU-28 in $2015,{ }^{3}$ reducing social inequalities is one of the objectives of 
the National Health Programme for 2016-2020. ${ }^{4}$ Socioeconomic factors are known to constitute a significant modifiable cause of the excess mortality among Polish residents. ${ }^{5}$

The most important causes of deaths and lost years of life in Poland include cardiovascular diseases, malignant neoplasms, external causes, respiratory diseases and diseases of the digestive system. ${ }^{67}$ The latter group is dominated by diseases related to excessive use of alcohol, that is, alcoholic liver disease, fibrosis and cirrhosis of the liver as well as acute pancreatitis. ${ }^{8}$ In view of the increasing per capita alcohol consumption in Poland, along with the growth of other unhealthy behaviours related to the Westernisation, further analyses of the influence of socioeconomic variables on mortality due to digestive diseases are required. ${ }^{910}$ To date, most research has been devoted to the assessment of the health situation of Polish citizens regarding cardiovascular diseases, and little attention has been paid to diseases of the digestive system. ${ }^{11} 12$

Currently, synthetic measures are increasingly used to assess the health of the population; WHO recommends using the Disability-adjusted Life Years measure and its components: years of life with disability and years of life lost (YLLs). The YLL measure better expresses the socioeconomic aspects of premature mortality than traditionally used death rates. It takes into account the number of deaths, and the age of the persons at the time of death. ${ }^{13}$

The aim of the study was to analyse the YLL score associated with diseases of the digestive system in Poland in 2002 and 2011 according to socioeconomic factors: marital status, level of education, working status and place of residence.

\section{METHODS}

The study was based on a dataset containing information gathered from the death certificates of Polish citizens who died in $2002(\mathrm{n}=359486)$ and in $2011(\mathrm{n}=375501)$, obtained from the Central Statistical Office in Poland. These years were included in the study because they were when the last two censuses of the Polish population took place. The database used in the study is available as online supplementary material 1 .

The analysis covered the data on deaths caused by diseases of the digestive system, that is, coded as K00-K93 according to the International Classification of Diseases and Related Health Problems-10th Revision (ICD-10): the numbers of deaths were 14772 in $2002(4.11 \%$ of all deaths) and 16434 in 2011 (4.38\%).

For both years, mortality rates were calculated and then standardised by age using the direct method, with the European population updated in 2013 as the reference. ${ }^{14}$ In order to evaluate the number of YLLs, the authors applied the Standard Expected Years of Life Lost (SEYLL) measure, calculated using a methodology consistent with GBD (according to the method developed by Murray and Lopez $)^{15}$ :

$$
\text { SEYLL }=\sum_{\chi=0}^{\mathrm{I}} \mathrm{d}_{\chi} \mathrm{e}_{\chi}^{*}
$$

where: $\mathrm{e}_{\chi}^{*}$ stands for a number of expected years of life that remain to be lived by the population which is at age $\mathrm{x} ; \mathrm{d}_{\chi}$ stands for a number of deaths at age $\chi ; \chi$ stands for the age when death occurred; I stands for the oldest age in a particular population.

The life expectancy for particular age was determined on the basis of the table published by WHO in 2012 . According to this source, the expected lifespan for both sexes at the age of 0 is 86.02 years. ${ }^{16}$

We also used the SEYLL per person (SEYLL ${ }_{\mathrm{p}}$ ) measure, which is the ratio of YLLs to the number of inhabitants, calculated in this study as a value per 10000 population.

In addition to the underlying cause of death, the following variables were included in the study: sex, age, place of residence, marital status, level of education and working status.

Area codes identifying place of residence were assigned to two variants:

- Urban area.

- Rural area.

Marital status was classified into four categories:

- Single.

- Married.

- Divorced/separated.

- Widowed.

In Poland, cohabitation cannot be chosen as the marital status of the deceased. However, Poland is characterised by a very low percentage of cohabitating couples. In 2011, there were about 320000 of them (approximately 2.1\% of the population were cohabitants), while in 2002 there were less than 200000 (1.4\% of the population). ${ }^{17}$

Levels of education consistent with the International Standard Classification of Education updated in 2011 were assigned to the stages of the Polish education system. ${ }^{18}$ Three levels of education were identified:

- Lower than secondary education (levels 0-2).

- Secondary education (levels 3-4).

- University education (levels 5-8).

Working status was classified as:

- Economically active (working or receiving unemployment benefits).

- Economically inactive (using non-commercial source of income or dependent on another person).

To calculate YLLs according to socioeconomic variables, data on deaths among inhabitants aged 15 years and above were used, because the information from the national censuses on the number of inhabitants according to the analysed variables (ie, marital status, level of education and working status) were limited to this age group. ${ }^{19} 20$ It should be noted that among children and adolescents under 15 years of age, 32 deaths were recorded for K00-K93 in 2002 and 6 deaths in 2011.

Some of the death certificates lacked the information on the variables covered by the study: 

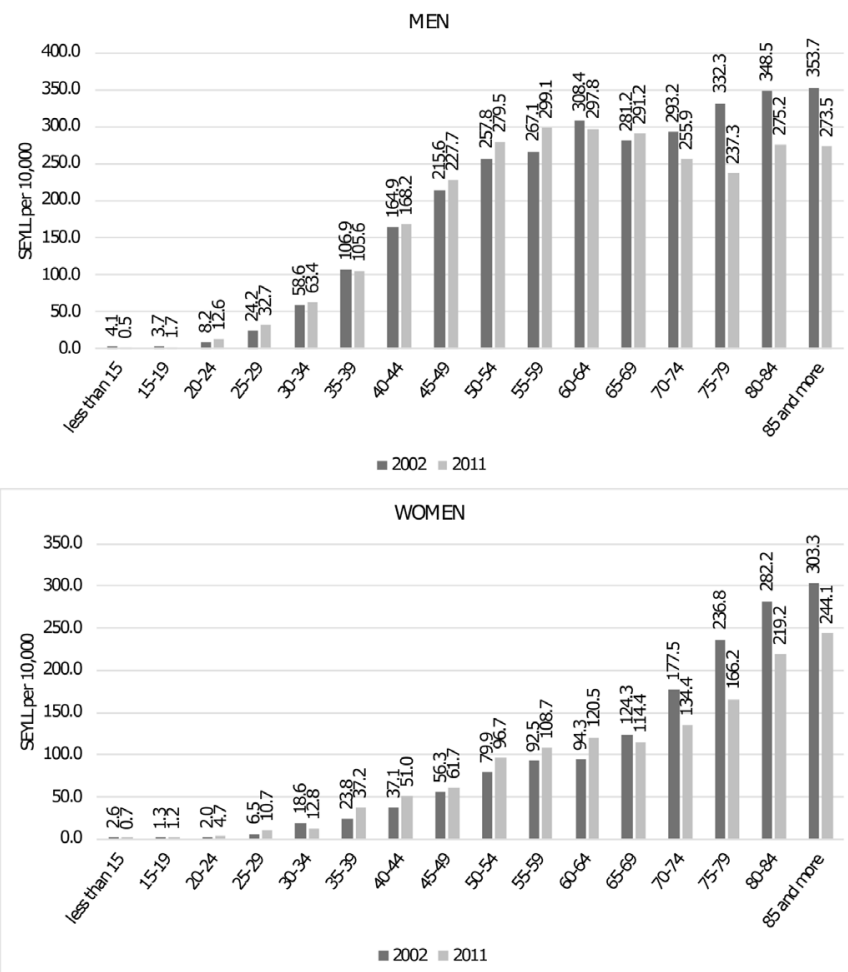

Figure 1 Years of life lost due to diseases of the digestive system in Poland according to age. SEYLL, standard expected years of life lost.

- Level of education was absent from $0.47 \%$ of certificates in 2002 and $1.50 \%$ in 2011.

- Marital status was complete in 2002, but was absent from $0.24 \%$ in 2011.

- Working status was absent from $0.37 \%$ of certificates in 2002 and $1.41 \%$ of certificates in 2011 .

- Place of residence was complete in both studied years.

For each socioeconomic variable, the rate ratio (RR) was calculated as the quotient of SEYLL in the less privileged group to SEYLL $\mathrm{p}_{\mathrm{p}}$ in the most privileged group; the corresponding $95 \%$ CIs were also calculated, these being estimated based on the formulas described by Morris and Gardner. $^{21} 22$

Patient and public involvement statement

Patients and Public were not involved in the study.

\section{RESULTS}

\section{General results}

Between 2002 and 2011 in Poland, the values of standardised death rates (SDRs) due to diseases of the digestive system decreased from 5.95 to 5.25 per 10000 people. In both analysed years, the crude death rates due to digestive diseases increased with age, reaching the highest values in people aged 85 and more. Progression of premature mortality due to these diseases was also observed, expressed as an increase in time (ie, between 2002 and 2011) of mortality rates among people aged up to 64 years, with a simultaneous decline in all subsequent age groups (online supplementary material 2 ).

Among the diseases of the digestive system, a highest number of deaths were due to liver diseases, responsible for 5494 deaths in 2002 (37.19\% of deaths caused by diseases of the digestive system) and 6941 deaths in 2011 $(42.24 \%)$. This group was dominated by alcoholic liver disease (1079 and 2968 deaths, respectively), as well as fibrosis and cirrhosis of the liver (3951 and 3320 deaths, respectively) (online supplementary 3 ).

The socioeconomic characteristics of deaths due to digestive diseases in inhabitants of Poland aged 15 years and above in 2002 and 2011 are presented in online supplementary 4.

Among people aged 15 years and above, in 2002, digestive diseases were the cause of 330098.72 YLLs in total $\left(\mathrm{SEYLL}_{\mathrm{p}}=101.02\right.$ years per 10000$): 220008.75$ years in men $\left(\mathrm{SEYLL}_{\mathrm{p}}=141.39\right.$ years $)$ and 110089.97 years in women $\left(\mathrm{SEYLL}_{\mathrm{p}}=64.30\right.$ years $)$. In 2011 , this figure was 373272.02 YLLs in total $\left(\mathrm{SEYLL}_{\mathrm{p}}=115.70\right.$ years): 249 639.37 years in men $\left(\mathrm{SEYLL}_{\mathrm{p}}=161.53\right.$ years $)$ and 123 632.65 years in women $\left(\right.$ SEYLL $_{\mathrm{p}}=73.55$ years).

In 2002, the highest $\mathrm{SEYLL}_{\mathrm{p}}$ values were found among the oldest members of the population, that is, at the age of 85 and above: 353.7 years for men and 303.3 years for women. In contrast, in 2011, the highest SEYLL $\mathrm{p}_{\mathrm{p}}$ was recorded in the 55-59 age group for men (299.1 years), but in the 85 and above age group for women (244.1 years). It is noteworthy that among men, SEYLL values increased over time in the 40-59 and 65-69 years group but decreased in subsequent age groups. Similarly, among

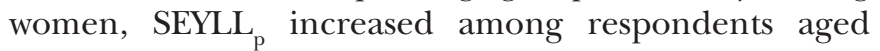
35-64 years and decreased in subsequent age groups (figure 1).

\section{YLLs according to marital status}

In both analysed years, the highest SEYLL $\mathrm{p}_{\mathrm{p}}$ values in men were observed in the divorced/separated group (657.87 years in 2002 and 689.32 years in 2011), and the lowest in the group of singles (100.63 years and 121.10 years, respectively); RR fell from 6.54 (95\% CI 6.44 to 6.63) in 2002 to 5.69 (95\% CI 5.62 to 5.76) in 2011. In women, the

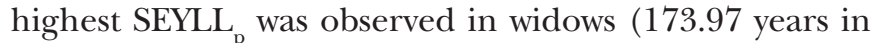
2002 and 169.46 years in 2011), and the lowest in singles (26.99 years and 33.33 years, respectively); the RR value also decreased from 6.45 (95\% CI 6.31 to 6.58) in 2002 to 5.08 in 2011 (95\% CI 4.99 to 5.18) (figure 2, table 1).

\section{YLLs according to level of education}

Among men, the highest SEYLL ${ }_{p}$ values were in those with lower than secondary education (178.85 years in 2002 and 198.32 years in 2011), and the lowest in those with higher education (54.20 years in 2002 and 57.66 years in 2011); the RR rose from 3.30 (95\% CI 3.23 to 3.37 ) in 2002 to 3.44 (95\% CI 3.38 to 3.50) in 2011. Similarly, in women, SEYLL ${ }_{\mathrm{p}}$ was the highest in those with lower than secondary education (104.95 years in 2002 and 125.76 years in 2011), and the lowest in those with higher 


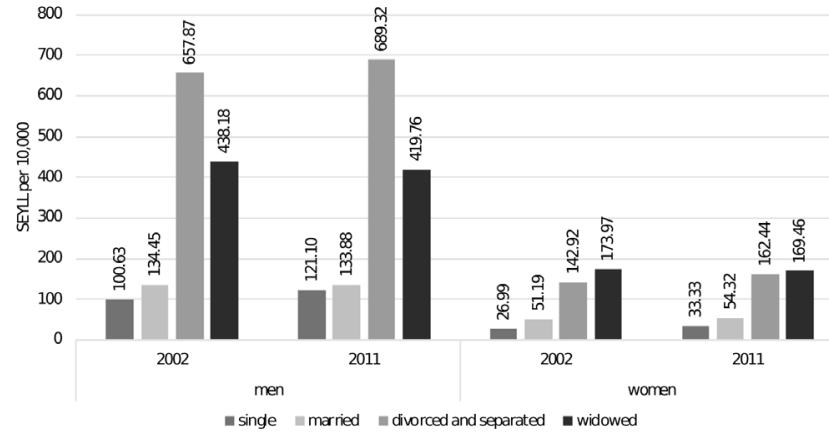

Figure 2 Years of life lost due to diseases of the digestive system in inhabitants of Poland aged 15 years and above in 2002 and 2011 according to marital status. SEYLL, standard expected years of life lost.

education (17.31 years and 18.31 years, respectively); RR increased from 6.06 (95\% CI 5.88 to 6.25 ) in 2002 to 6.87 (95\% CI 6.70 to 7.04 ) in 2011 (figure 3 ).

\section{YLLs according to working status}

In both sexes, being economically inactive was associated with a greater YLL score than being economically active. SEYLL fell from 340.54 years among inactive men in 2002 to 219.93 years in 2011, and rose from 36.93 years to 59.51 years among active men; the RR value decreased from 9.22 (95\% CI 9.11 to 9.33$)$ in 2002 to 3.69 (95\% CI 3.66 to 3.73) in 2011. SEYLL fell from 126.86 years among inactive women in 2002 to 96.80 years in 2011, and rose from 10.31 years to 14.96 years among active women; the

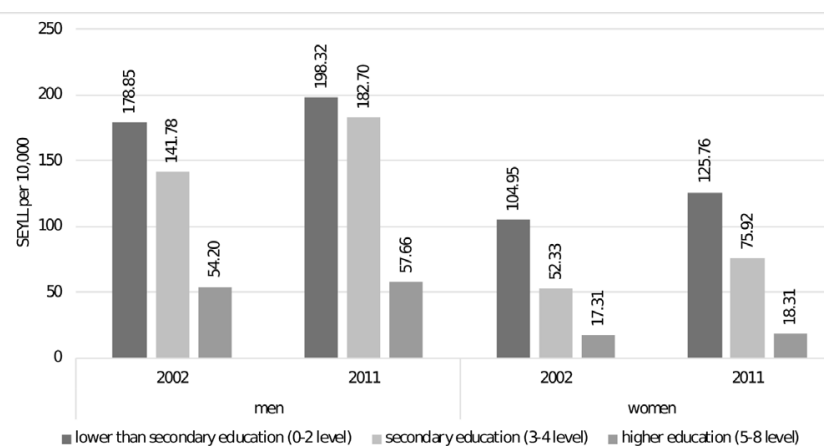

Figure 3 Years of life lost due to diseases of the digestive system in inhabitants of Poland aged 15 years and above in 2002 and 2011 according to level of education. SEYLL, standard expected years of life lost.

RR value fell from 12.31 (95\% CI 12.03 to 12.59) in 2002 to 6.47 (95\% CI 6.35 to 6.59 ) in 2011 (figure 4 ).

\section{YLLs according to place of residence}

Among men, SEYLL $\mathrm{p}_{\mathrm{p}}$ was 159.46 years in 2002 and 174.18 years in 2011 among urban residents, and 126.83 years and 137.11 years among rural residents; the $R R$ value was 1.26 (95\% CI 1.25 to 1.27 ) in 2002 and 1.27 (95\% CI 1.26

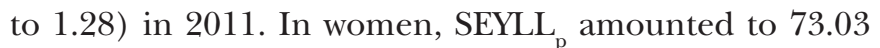
years in 2002 and 78.12 years in 2011 among urban residents, and 57.32 years and 57.56 years among rural residents; the RR value grew from 1.27 (95\% CI 1.26 to 1.29 ) in 2002 to 1.36 (95\% CI 1.34 to 1.37) in 2011 (figure 5).

Table 1 Socioeconomic inequalities in years of life lost due to diseases of the digestive system in inhabitants of Poland aged 15 years and above in 2002 and 2011

\begin{tabular}{|c|c|c|c|c|}
\hline & \multicolumn{4}{|l|}{ Rate ratio $(95 \% \mathrm{Cl})$} \\
\hline & \multicolumn{2}{|l|}{ Men } & \multicolumn{2}{|l|}{ Women } \\
\hline & 2002 & 2011 & 2002 & 2011 \\
\hline \multicolumn{5}{|l|}{ Level of education } \\
\hline $\begin{array}{l}\text { Less than secondary } \\
\text { education }\end{array}$ & 3.30 (3.23 to 3.37$)$ & 3.44 (3.38 to 3.50$)$ & 6.06 (5.88 to 6.25$)$ & 6.87 (6.70 to 7.04 ) \\
\hline Secondary education & 2.62 (2.56 to 2.67 ) & 3.17 (3.12 to 3.22 ) & 3.02 (2.93 to 3.12 ) & 4.15 (4.05 to 4.25 ) \\
\hline University education & 1.00 & 1.00 & 1.00 & 1.00 \\
\hline \multicolumn{5}{|l|}{ Marital status } \\
\hline Single & 1.00 & 1.00 & 1.00 & 1.00 \\
\hline Married & 1.34 (1.32 to 1.35$)$ & 1.11 (1.09 to 1.12$)$ & 1.90 (1.86 to 1.94$)$ & 1.63 (1.60 to 1.66$)$ \\
\hline Divorced/separated & 6.54 (6.44 to 6.63$)$ & 5.69 (5.62 to 5.76$)$ & 5.30 (5.15 to 5.44$)$ & 4.87 (4.76 to 4.99$)$ \\
\hline Widowed & 4.35 (4.28 to 4.43$)$ & 3.47 (3.41 to 3.52 ) & 6.45 (6.31 to 6.58$)$ & 5.08 (4.99 to 5.18 ) \\
\hline \multicolumn{5}{|l|}{ Working status } \\
\hline Economically active & 1.00 & 1.00 & 1.00 & 1.00 \\
\hline Economically inactive & 9.22 (9.11 to 9.33$)$ & 3.69 (3.66 to 3.73 ) & 12.31 (12.03 to 12.59$)$ & 6.47 (6.35 to 6.59$)$ \\
\hline \multicolumn{5}{|l|}{ Place of residence } \\
\hline Urban area & 1.00 & 1.00 & 1.00 & 1.00 \\
\hline Rural area & 1.26 (1.25 to 1.27$)$ & 1.27 (1.26 to 1.28$)$ & 1.27 (1.26 to 1.29$)$ & 1.36 (1.34 to 1.37$)$ \\
\hline
\end{tabular}




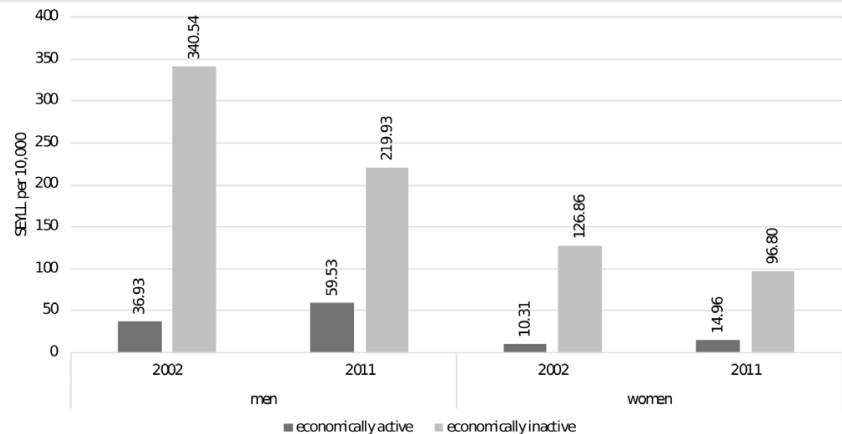

Figure 4 Years of life lost due to diseases of the digestive system in inhabitants of Poland aged 15 years and above in 2002 and 2011 according to working status. SEYLL, standard expected years of life lost.

\section{DISCUSSION}

Between 2002 and 2011, the values of SDRs for diseases of the digestive system in Poland decreased. However, the increase in death rates observed among people aged 20-64 due to digestive diseases was reflected in a relevant increase in YLLs.

To most effectively prevent deaths in the least privileged groups, it is necessary to identify the features that contribute most to premature loss of life. Our findings indicate that among the Polish population, male sex, divorced or widowed marital status, lower than secondary education, economic inactivity and living in urban areas have the most unfavourable effect on YLL score due to digestive diseases.

In both sexes, differences in YLL values due to digestive diseases between particular socioeconomic groups, measured with RR, increased over time between people who differed in the level of education or place of residence, and they decreased between people from different categories of marital status and working status.

Our findings indicate that alcohol-related liver diseases, that is, alcoholic liver disease and fibrosis and cirrhosis of the liver have the dominant influence on YLL score due to diseases of the digestive system. In Poland, alcohol consumption has been increasing in recent years, which may partially explain the change in YLLs due to digestive diseases, and the growing inequalities between some socioeconomic groups: mean alcohol consumption rose from 8.02 L of pure alcohol per person in 2002 to 10.11 $\mathrm{L}$ in $2011 .^{23}$ In addition, in 2008, men in Poland drank on average 4.5 times more alcohol than women, most of them being divorced, with secondary vocational education, and worse financial situation in self-evaluation than women. $^{24}$

Mackenbach et al reported that in all of 17 surveyed European countries, deaths from alcohol-related diseases (including alcoholic liver cirrhosis) were more common in people with lower levels of education. ${ }^{25}$ Research conducted on British and American populations found divorced and widowed people to have higher risk of liver dysfunction (self-reported impaired liver condition) than those of other relationship status, while singles displayed

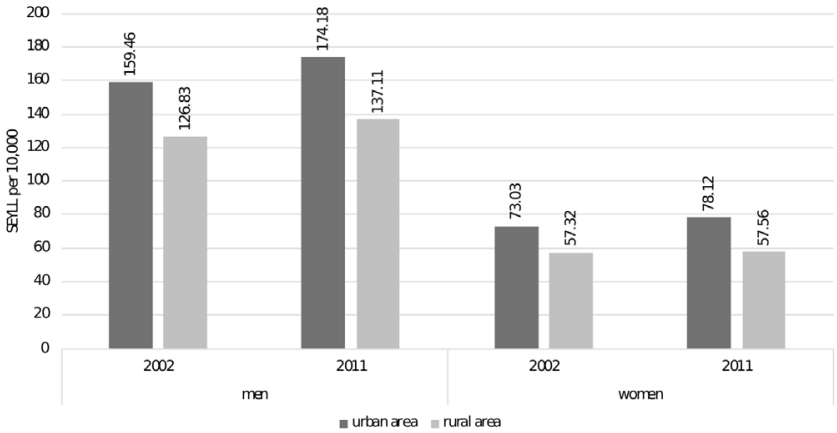

Figure 5 Years of life lost due to diseases of the digestive system in inhabitants of Poland aged 15 years and above in 2002 and 2011 according to place of residence. SEYLL, standard expected years of life lost.

the lowest risk. ${ }^{26}$ In addition, Johnson et al reported that marriage tended to have a protective effect against hospitalisation and death due to liver cirrhosis, and suggested that married patients are more likely to follow medical prescriptions, including regular intake of drugs. ${ }^{27} \mathrm{~A}$ Hungarian study found a higher risk of chronic liver disease and liver cirrhosis to be associated with being single, separated or divorced, and having lower level of education. It was stated that behaviours related to alcohol consumption do not fully explain the existing health inequalities. $^{28}$

Other studies have confirmed that people with lower socioeconomic status have a greater risk of adverse health effects associated with drinking alcohol than more privileged inhabitants, even though both groups may consume the same amount of alcohol; hence, the term 'alcohol-harm paradox'. Although the causes remain unclear, it has been observed that the type of drink consumed and the style of drinking (binge drinking among people with lower socioeconomic status) may play a role, together with the coexistence of other diseases and health problems, and access to medical care. ${ }^{29} 30$

It should be noted that although all citizens in Poland have equal access to publicly funded healthcare, its availability has been limited in recent years due to low funding, amounting to $4.8 \%$ of gross domestic product (GDP), compared with an EU average of $6.7 \%$ in 2016, and insufficient staff numbers between 2000 and 2016, it was 2.4 doctors per 1000 inhabitants, significantly lower than the EU average of between 3.0 and 3.6, respectively, and 5.2 nurses per 1000 population with an EU average being 6.5 and 8.4, respectively. Due to long waiting periods for specialist treatment, the interest of Polish inhabitants in the private healthcare sector is growing. Its availability depends on the material situation of the patients; hence, the described inequalities in health between citizens differing in socioeconomic status may be associated with uneven access to high-quality and timely medical care. ${ }^{31} 32$

On the other hand, recent years have seen a gradual improvement in the economic situation of Polish citizens between 1990 and 2014, GDP grew by an average of $3.8 \%$ annually. YLL score among economically inactive people 
of both sexes were found to decrease during this period, while those of economically active people increased; this suggests that the least privileged inhabitants tended to gain more health benefits as an effects of economic growth. ${ }^{33}$

A research conducted on a Danish population, characterised by high economic status with small socioeconomic inequalities, revealed higher mortality among people with lower education in relation to university graduates. This unfavourable epidemiological situation was considered to be due to behaviours related to alcohol consumption and cigarette smoking. ${ }^{34}$

Smoking has a proven negative impact on the development of many disorders, particularly respiratory and cardiovascular diseases; however, it also increases the risk of chronic digestive diseases and exacerbates their course. $^{35}{ }^{36}$ A study conducted on a Polish population found a higher percentage of daily-smokers among men with lower socioeconomic status (beneficiaries of social institutions) than in the general male population, that is, $52.8 \%$ vs $33.9 \%^{37}$; even greater differences were revealed by a study on an Australian population: $53.5 \%$ vs $15.1 \% .^{38}$

The reasons for the worsening epidemiological situation due to digestive disease, in terms of YLL score, may also be incorrect eating habits. Numerous studies have proved that people with low socioeconomic status are more likely to have difficulty balancing their daily diet. ${ }^{39}$ The second edition of the Multi-Centre National Population Health Examination Survey carried out in 2013-2014 showed that about $60 \%$ of Polish residents consume a low-quality diet (0-3 points in the 7-point Healthy Diet Indicator), and only $15 \%$ of the population incorporate healthy eating habits (5-7 points). ${ }^{40}$

Regardless of the type of analysed socioeconomic variable, men lost on average more years of life than women. This can be explained by a greater intensity of adverse health behaviours among men (such as poor diet, cigarette smoking and alcohol consumption), and also by less frequent use of healthcare due to low attention paid to disease symptoms. ${ }^{41}$

Income differences may also play an important role while discussing health inequalities between men and women. In 2017, in Poland, the gender pay gap amounted to 7.2, indicating that women earned, on average, $7.2 \%$ less than men per hour of work; however, according to the Central Statistical Office in Poland, mean hourly wages were reported to be $13.9 \%$ grater among men than women in 2014. It is recognised that in Poland, maternity has the greatest influence on depressing earnings by women; even so motherhood can be considered as a protective factor against various risk behaviours, including excessive consumption of alcohol, which may also have some impact on inequalities in YLL score according to sex. ${ }^{42} 43$

Although both sexes displayed an increasing trend of RR according to the level of education, this index was higher in women than in men. This is a consequence of a greater increase in $\mathrm{SEYLL}_{\mathrm{p}}$ over time among people with less than secondary education (about 20\% among women and $11 \%$ among men), compared with people with higher education (about 6\% in both sexes). This indicates that the health situation of the least-educated women was deteriorating particularly quickly; this may be associated with an unfavourable financial situation and greater participation in adverse health behaviours among this group. However, it should be noted that in the analysed years, the percentage of women with higher education increased from $15.3 \%$ to $24.6 \%$, and the percentage of women with lower than secondary education dropped from $36.4 \%$ to $25.6 \%$. It can, therefore, be assumed that the actual effects of the described social inequalities are less noticeable than indicated by the RR analysis. It should be emphasised that surveys of the Polish population indicate that women with higher education are characterised by the best health condition due to the most health-oriented lifestyle. ${ }^{104-46}$

\section{Limitations}

The research material comprised a dataset created on the basis of death certificates, the reliability of which depends on the correctly identification of the causes of deaths and their accurate coding (according to ICD-10). It has been proposed that the most pronounced inaccuracies in determining causes of death in the Polish population concern cardiovascular diseases ${ }^{77}$; however, a study comparing YLL values due to alcohol-related liver diseases between individual Polish provinces found significantly lower recognition of fibrosis and cirrhosis of the liver in one province, with a relatively high number of alcoholic liver disease cases. ${ }^{48}$

In addition, some death certificates lack information on level of education, marital status or employment status. However, given the very large number of the database, the data gaps discussed in the present study did not have a significant impact on the research results.

Another disadvantage of research on YLLs is related to discrepancies in the methodology used by different authors, which may make it difficult to compare the obtained results. To compute YLLs, it is possible to use, instead of SEYLL, the Potential Years of Life Lost measure, where the value of life between 60 and 85 years of age is taken as a limit, or the Period Expected Years of Life Lost measure, which uses local life tables for this purpose. In addition, when using SEYLL, it is possible to base the analysis on different reference points, such as the Cole-Demeny's life tables based on the Japanese population or tables with reference values based on the EU-15 or EU-27 averages. ${ }^{49}$

\section{CONCLUSIONS}

Substantial health inequalities exist between most socioeconomic groups in the Polish population with regard to YLL scores due to diseases of the digestive system. Such differences observed between inhabitants with different levels of education imply the need to direct public health activities primarily at people with lower than secondary 
education, but also at divorced and widowed people, residents of urban areas, and those who are economically inactive. Particular emphasis should be placed on modification of lifestyle behaviours, which seem to play a crucial role in premature mortality due to diseases of the digestive system, including combating alcohol addiction, cigarette smoking cessation and diet modification. Further research should be directed at seeking other causes of identified socioeconomic inequalities.

Contributors All authors contributed to the writing of the manuscript. PP-G as a first author was responsible for statistical analysis, data interpretation and literature search. MP was responsible for the study design, data collection and statistical analysis. IM-B participated in the study design and literature search.

Funding This work was supported by the Medical University of Lodz on the basis of grant number 503/6-029-07/503-61-001.

Competing interests None declared.

Patient consent for publication Not required.

Ethics approval The Bioethics Committee of the Medical University of Lodz gave consent for the research to be conducted (No. RNN/183/ 17KE of 13 June 2017).

Provenance and peer review Not commissioned; externally peer reviewed.

Data availability statement All data relevant to the study are included in the article or uploaded as online supplementary information.

Open access This is an open access article distributed in accordance with the Creative Commons Attribution Non Commercial (CC BY-NC 4.0) license, which permits others to distribute, remix, adapt, build upon this work non-commercially, and license their derivative works on different terms, provided the original work is properly cited, appropriate credit is given, any changes made indicated, and the use is non-commercial. See: http://creativecommons.org/licenses/by-nc/4.0/.

\section{REFERENCES}

1. Wang $H$, Naghavi $M$, Allen $C$, et al. Global, regional, and national life expectancy, all-cause mortality, and cause-specific mortality for 249 causes of death, 1980-2015: a systematic analysis for the global burden of disease study 2015. The Lancet 2016;388:1459-544.

2. Commission on Social Determinants of Health. Closing the gap in a generation: health equity through action on the social determinants of health. final report of the Commission on social determinants of health. Geneva: World Health Organization, 2008.

3. Eurostat Statistics, Luxembourg. Mortality and life expectancy statistics, 2017. Available: http://ec.europa.eu/eurostat/statisticsexplained/index.php/Mortality_and_life_expectancy_statistics [Accessed 15 Nov 2018].

4. National health program 2016-2020. Available: www.mz.gov.pl/ zdrowie-i-profilaktyka/narodowy-program-zdrowia/npz-2016-2020/ [Accessed 15 Nov 2018].

5. Pikala M, Maniecka-Bryła I. [Socioeconomic inequalities in mortality due to all causes in the working age population of Poland in 2002 and 2011]. Med Pr 2017;68:771-8.

6. Central Statistical Office in Poland. Local data bank, Warsaw. Available: http://www.bdl.stat.gov.pl [Accessed 10 Nov 2018]

7. Pikala M, Maniecka-Bryła I. Fifteen-year mortality trends in Poland analysed with the use of standard expected years of life lost, 20002014. Sci Rep 2017;7:8730.

8. Paciej-Gołębiowska P, Pikala M, Maniecka-Bryła I. Years of life lost due to diseases of the digestive system in Poland in 2000-2014. J Gastrointestin Liver Dis 2018;27:419-25.

9. Stepaniak U, Micek A, Waśkiewicz A, et al. Prevalence of general and abdominal obesity and overweight among adults in Poland. Results of the WOBASZ II study (2013-2014) and comparison with the WOBASZ study (2003-2005). Pol Arch Med Wewn 2016;126:662-71.

10. Kwaśniewska M, Pikala M, Bielecki W, et al. Ten-Year changes in the prevalence and socio-demographic determinants of physical activity among Polish adults aged 20 to 74 years. Results of the National multicenter health surveys WOBASZ (2003-2005) and WOBASZ I (2013-2014). PLoS One 2016;11:e0156766.

11. Kozakiewicz K, Podolecka E, Kwaśniewska M, et al. Association between socioeconomic status and cardiovascular risk. Kardiol Pol 2016;74:179-84.
12. Pikala M, Kaleta D, Bielecki W, et al. Awareness of cardiovascular prevention methods among residents of post-communist Polish provinces with highest mortality rates. Cent Eur J Public Health 2011;19:183-9.

13. Kassebaum NJ, Arora M, Barber RM, et al. Global, regional, and national disability-adjusted life-years (DALYs) for 315 diseases and injuries and healthy life expectancy (HALE), 1990-2015: a systematic analysis for the global burden of disease study 2015. The Lancet 2016;388:1603-58.

14. Eurostat. Revision of the European Standard Population Report of Eurostat's task force. Luxembourg: Publications Office of the European Union, 2013.

15. Murray CJL, Lopez AD. The Global Burden of Disease. A comprehensive assessment of mortality and disability from diseases, injuries and risk factors in 1990 and projected to 2010. Boston: Harvard University Press, 1996.

16. Murray CJL, Ezzati M, Flaxman AD, et al. GBD 2010: design, definitions, and metrics. The Lancet 2012;380:2063-6.

17. Central Statistical Office in Poland. Marriages and fertility in Poland, Warsaw, 2016. Available: https://stat.gov.pl/obszary-tematyczne/ ludnosc/ludnosc/malzenstwa-i-dzietnosc-w-polsce,23,1.html [Accessed 15 Apr 2019].

18. International Standard Classification of Education 2011. Montreal, UNESCO Institute for statistics, 2012. Available: http://uis. unesco.org/sites/default/files/documents/international-standardclassification-of-education-isced-2011-en.pdf [Accessed 10 Nov 2018].

19. European statistical system, Luxembourg. Available: https://ec. europa.eu/CensusHub2/query.do?step=selectHyperCube\&qhc=false [Accessed 10 Nov 2018].

20. Central Statistical Office in Poland. National census 2002, Warsaw. Available: http://stat.gov.pl/spisy-powszechne/narodowe-spisypowszechne/narodowy-spis-powszechny-2002/ [Accessed 20 Nov 2018]

21. Morris JA, Gardner MJ. Calculating confidence intervals for relative risks (odds ratios) and standardised ratios and rates. Br Med J 1988;296:1313-6.

22. Mackenbach JP, Kunst AE. Measuring the magnitude of socioeconomic inequalities in health: an overview of available measures illustrated with two examples from Europe. Soc Sci Med 1997:44:757-71.

23. European Health for All database (HFA-DB). Who regional office for Europe, Copenhagen. Available: www.euro.who.int/hfadb [Accessed November 21, 2018].

24. State Agency for the Prevention of Alcohol-Related Problems. Patterns of alcohol consumption in Poland, 2008. Available: http://www.parpa.pl/download/wyniki\%20badania\%20wzory\% 20konsumnpscji\%202008_\%202\%20metody_poprMFdoc.pdf [Accessed 21 Nov 2018].

25. Mackenbach JP, Kulhánová I, Bopp M, et al. Inequalities in alcoholrelated mortality in 17 European countries: a retrospective analysis of mortality registers. PLoS Med 2015;12:e1001909.

26. Shiue I, Age SI. Age, sex and marital status are associated with self-reported liver condition in adults: national surveys in the UK and USA, 2009-2010. Public Health 2015;129:276-9.

27. Johnson KB, Campbell EJ, Chi H, et al. Advanced disease, diuretic use, and marital status predict hospital admissions in an ambulatory cirrhosis cohort. Dig Dis Sci 2014;59:174-82.

28. BÉ P, Széles G, Melles M, et al. Bahaviour does not fully explain the high risk of chronic liver disease in less educated men in Hungary. Eur J Public Health 2011;21:662-6.

29. Katikireddi SV, Whitley E, Lewsey J, et al. Socioeconomic status as an effect modifier of alcohol consumption and harm: analysis of linked cohort data. The Lancet Public Health 2017;2:e267-76.

30. Jones L, Bates G, McCoy E, et al. Relationship between alcoholattributable disease and socioeconomic status, and the role of alcohol consumption in this relationship: a systematic review and meta-analysis. BMC Public Health 2015;15:400.

31. OECD/European Observatory on Health Systems and Policies. Poland: country health profile 2017. Brussels: OECD Publishing, Paris/European Observatory on Health Systems and Policies, 2017.

32. OECD/EU, Health at a Glance. Europe 2018: state of health in the EU cycle. Brussels: OECD Publishing, 2018. https://doi.org/. (Accessed April 17, 2019).

33. Korbonski A. East central Europe on the eve of the changeover: the case of Poland. Communist Post-Communist Stud 1999;32:139-53.

34. Koch MB, Diderichsen F, Gronbaek M, et al. What is the association of smoking and alcohol use with the increase in social inequality in mortality in Denmark? A nationwide register-based study. BMJ Open 2015:5:e006588. 
35. LF L, Chan RL, Lu L, et al. Cigarette smoking and gastrointestinal diseases: the causal relationship and underlying molecular mechanisms (review). Int J Mol Med 2014;34:372-80.

36. Parkes GC, Whelan K, Lindsay JO. Smoking in inflammatory bowel disease: impact on disease course and insights into the aetiology of its effect. Journal of Crohn's and Colitis 2014;8:717-25.

37. Milcarz K, Makowiec-Dąbrowska T, Bạk-Romaniszyn L, et al. Smoking patterns and smoking cessation Willingness - A study among beneficiaries of government welfare assistance in Poland. Int J Environ Res Public Health 2017;14:131.

38. Bryant J, Bonevski B, Paul C. A survey of smoking prevalence and interest in quitting among social and community service organisation clients in Australia: a unique opportunity for reaching the disadvantaged. BMC Public Health 2011;11:827.

39. Giskes K, Avendaňo M, Brug J, et al. A systematic review of studies on socioeconomic inequalities in dietary intakes associated with weight gain and overweight/obesity conducted among European adults. Obes Rev 2010;11:413-29.

40. Waśkiewicz A, Szcześniewska D, Szostak-Węgierek D, et al. Are dietary habits of the Polish population consistent with the recommendations for prevention of cardiovascular disease? WOBASZ II project. Kardiol Pol 2016;74:969-77.

41. Quaife SL, Forbes LJL, Ramirez AJ, et al. Recognition of cancer warning signs and anticipated delay in help-seeking in a population sample of adults in the UK. Br J Cancer 2014;110:12-18.
42. Eurostat statistics, Luxembourg.. Available: https://ec.europa.eu/ eurostat/statistics-explained/index.php/Gender_pay_gap_statistics\# Gender_pay_gap_levels_vary_significantly_across_EU [Accessed April 18, 2019].

43. Oquendo MA, Bongiovi-Garcia ME, Galfalvy $\mathrm{H}$, et al. Sex differences in clinical predictors of suicidal acts after major depression: a prospective study. AJP 2007;164:134-41.

44. Mackenbach JP, Kulhánová I, Menvielle G, et al. Trends in inequalities in premature mortality: a study of 3.2 million deaths in 13 European countries. J Epidemiol Community Health 2015;69:207-17.

45. Wojtyniak B, Moskalewicz J, Stokwiszewski J, et al. Gender-Specific mortality associated with alcohol consumption in Poland in transition. Addiction 2005;100:1779-89.

46. Dziankowska-Zaborszczyk E, Bryła M, Maniecka-Bryła I. Zależność między paleniem tytoniu I piciem alkoholu a ryzykiem zgonu osób W wieku produkcyjnym - wyniki 8-letniego badania W dużej aglomeracji miejskiej. Med Pr 2014;65:251-60.

47. Wojtyniak B, Jankowski K, Zdrojewski T, et al. Regional differences in determining cardiovascular diseases as the cause of death in Poland: time for change. Kardiol Pol 2012;70:695-701.

48. Paciej P, Ciabiada B, Maniecka-Bryła I. Premature mortality due to alcohol-related diseases of the liver in Poland according to voivodships. Fmpcr 2017:3:251-5.

49. Bryła M, Dziankowska-Zaborszczyk E, Bryła P, et al. Years of life lost due to infectious diseases in Poland. PLoS One 2017;12:e0174391. 